\title{
How Does a Key Fit a Flexible Lock? Structure and Dynamics in Receptor Function
}

\author{
Richard R. Neubig and William J. Thomsen
}

\section{Summary}

The preceding five years have brought remarkable advances in our understanding of the primary structure of drug receptors. The roles of certain amino acid residues in binding drugs and effecting receptor function have been proposed. As even more detailed structures become available, the goal of rational design of drug molecules based on predicted fits between the drug and its receptor will be near at hand. Although none of the classical receptors has yet yielded to $X$ ray crystallographic analysis, the methods of molecular biology facilitate the production of the large amounts of these rare proteins necessary for crystallization. Receptor proteins share one fundamental characteristic with allosterically regulated enzymes. Both have the structural flexibility that allows information to be transmitted to distant parts of the molecule. We will discuss recent observations about receptor structure and the dynamic nature of drug receptors, and pose questions about the significance of receptor dynamics for drug design.

\section{Receptor Structure}

Classical drug receptors are plasma membrane proteins which bind agonist or antagonist drugs leading, in the former case, to the production of an intracellular signal. The receptors for insulin $^{1}$ and acetylcholine ${ }^{2}$ were the first membrane receptors to be purified. This established a biochemical identity for what had previously been theoretical entities. These two receptors were also among the first for which the entire primary amino acid sequence of the protein was determined. In both cases the powerful techniques of molecular biology were used to find the protein sequence indirectly by sequencing a complementary DNA (cDNA) derived from the mRNA coding for the protein. This approach has resulted in a plethora of information about the primary structure of rare plasma membrane recep- tors, including those for adrenaline ( $\beta$ adrenergic and $\alpha$-adrenergic), ${ }^{3}$ muscarin $^{4}$ (another type of acetylcholine receptor), epidermal growth factor $(\text { EGF })^{5}$ and a peptide hormone derived from the heart, atrial natriuretic factor. ${ }^{6}$

This structural information has also shed light on receptor mechanisms since sequence similarities have been found between receptors which share common mechanisms. This is even the case for receptors not previously thought to be related such as the classical $\beta$-adrenergic receptor (AR) and rhodopsin, the receptor for photons in the retina. ${ }^{3,7}$ Both proteins contain seven stretches of hydrophobic amino acids that are predicted to span the lipid bilayer by hydropathicity analysis. Indeed it is now recognized that the mechanism of signal transduction by both of these proteins involves a guanine nucleotide binding regulatory protein (G protein). In fact, a whole family of receptors exerts their effects through activation of a $G$ protein. ${ }^{8}$ Those for which the amino acid sequence is known all have seven hydrophobic regions and sequence homologies to the $\beta$ AR and rhodopsin.,.$^{3,4}$

Three other receptor families have related functional mechanisms and share significant sequence homology (Fig. 1). The first consists of multisubunit receptors that contain ion channels within their structure. The nicotinic acetylcholine receptor, when activated, allows passage of tremendous numbers of sodium ions $\left(>10^{6}\right.$ per second) through the plasma membrane. ${ }^{2}$ The receptors for gamma aminobutyric acid (GABA) and the amino acid neurotransmitter glycine carry chloride anions in a similar manner. Surprisingly, these anion transporters have significant structural similarities and sequence homologies with the cation carrying nicotinic acetylcholine receptor. ${ }^{9}$ The second family includes receptors that contain within their structure the enzymatic activity for tyrosine kinase. ${ }^{5}$ Receptors for a wide variety of growth factors, including insulin, EGF, platelet derived growth factor (PDGF) and colony stimulating factor (CSF) fall into this category. The third group has the fewest known members. It consists of receptors that contain the membrane-bound enzyme guanylate cyclase. Two examples are the receptors for atrial natriuretic peptide and the sea urchin egg peptide speractin. ${ }^{6}$ This classification based on transduction mechanism was given a solid structural basis as the similarities in primary sequence of several receptors in each class were identified. As new receptor sequences are determined, the classification of the receptors in this structural/

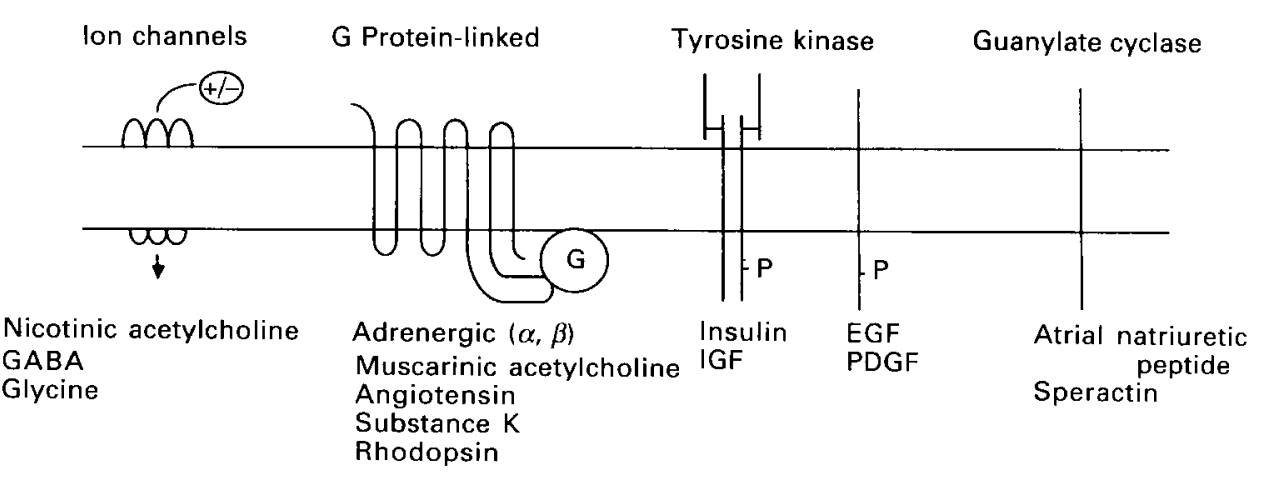

Fig. 1. Receptor families identified by structure and function. Membrane receptors for which deduced amino acid sequences are known can be divided into families based on their primary structure and biochemical mechanism. Structural features such as the presence of multiple subunits and the number and arrangement of hydrophobic (putative membrane spanning) helices are similar among members of a family of receptors with a common functional mechanism (see text for details). 
REVIEW ARTICLES

functional framework will no doubt further clarify the scheme.

As of yet, the primary sequence of a protein cannot be parlayed into its 3dimensional structure which includes secondary ( $\alpha$ helices, $\beta$ sheets etc.), tertiary and quaternary elements of the protein structure. The receptor for which the quaternary structure is best known is the nicotinic acetylcholine receptor. Because of its near crystalline arrangement in membranes of the electric organs of the marine ray Torpedo, electron microscopic imaging has yielded an $18 \AA$ resolution structural map of this receptor. ${ }^{10}$ This resolution is sufficient to localize the five subunits of the receptor and to trace their orientation in the membrane. The gross conformational change which accompanies desensitization of the nicotinic acetylcholine receptor by prolonged exposure to agonist has been visualized directly by such reconstruction of electron microscopic images. ${ }^{10}$ Despite this, there is still controversy regarding the topology of the nicotinic acetylcholine receptor in the membrane. ${ }^{11}$ Much improved images or single crystal X-ray studies will be necessary to localize the peptide backbone and determine the structure of the amino acid side chains that make up the acetylcholine binding site.

Predictions of the secondary and tertiary structure of the $G$ protein linked receptors, rhodopsin and the $\beta$ AR, have been made based on a $7 \AA$ map of bacteriorhodopsin. ${ }^{12}$ Although the latter is only very weakly related to rhodopsin, it has been shown to have seven transmembrane alpha helices and serves as a paradigm for the structure of the $G$ protein-coupled receptors. The model of the seven membrane spanning regions for rhodopsin and the $\beta \mathrm{AR}$ has been partially validated by affinity labelling, proteolysis and antibody methods $^{7,13}$ (Fig. 2). Based on these theoretical predictions and data obtained from mutagenesis and protein modification studies, models for the ligand binding site of the $\beta$ AR have been proposed. The most striking aspect of these models is that the agonist and antagonist drugs do not bind to the extracellular surface of the receptor. Rather, they bind to a site deep in the core of the receptor ${ }^{3}$ which requires the ligand to partially traverse the membrane by entering a pocket in the receptor. In bovine rhodopsin, the retinal is covalently attached by a Schiff base linkage to lys 296 in the middle of the seventh predicted membrane spanning region.? The site within the $\beta$

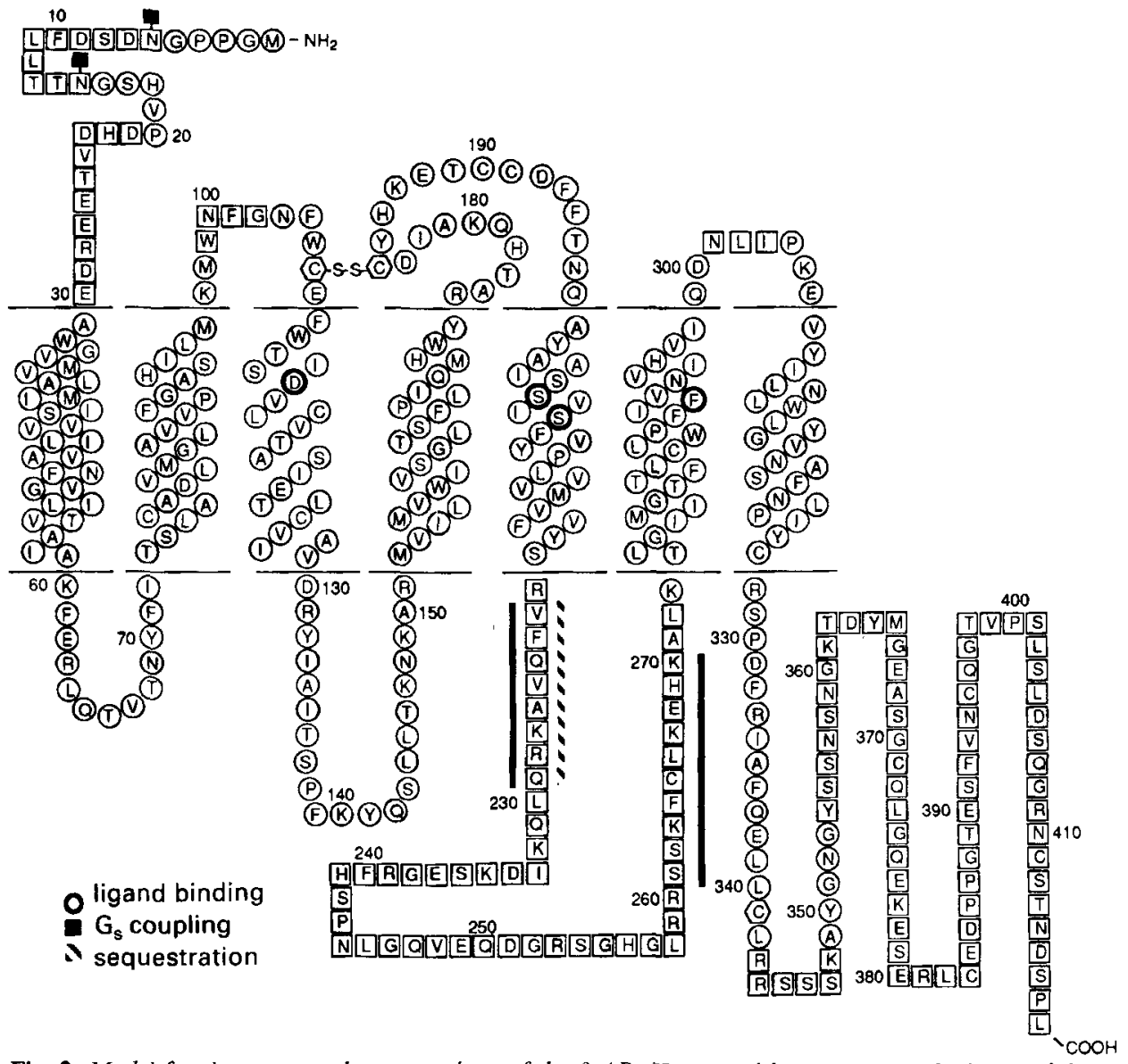

Fig. 2. Model for the transmembrane topology of the $\beta A R$. Horizontal lines represent the limits of the plasma membrane of the cell with the region at the top of the page corresponding to the extracellular space and the region at the bottom representing the cytoplasm. In this model, the receptor has seven transmembrane helices, with the amino terminal end of the protein exposed extracellularly and the carboxyl terminal end intracellularly. The amino acid residues represented by squares could be deleted from the protein without affecting ligand binding or protein folding, whereas the deletion of those residues shown in circles adversely affected either the folding or binding properties of the receptor. The residues shown in bold faced circles are proposed to be involved in interactions with the ligand. The regions of the third intracellular loop delineated by the solid stripe were determined to be critical for $G$ protein coupling, whereas the region delineated by the broken stripe was required for agonist mediated sequestration (i.e. desensitization). Figure and legend modified from reference 3 by permission of The FASEB Journal Vol. 3. p. 1826, 1989.

$T A B L E$ 1. Classification of membrane receptors by amino acid sequence and function

\begin{tabular}{|c|c|c|c|}
\hline Receptor type & Structural feature & Examples & Effector systems \\
\hline G protein-linked & $\begin{array}{l}7 \text { hydrophobic } \\
\text { domains }\end{array}$ & $\begin{array}{l}\alpha \text { Adrenergic } \\
\beta \text { Adrenergic } \\
\text { Muscarinic acetyl- } \\
\text { choline } \\
\text { Opiate } \\
\text { Angiotensin } \\
\text { Substance K } \\
\text { Rhodopsin }\end{array}$ & 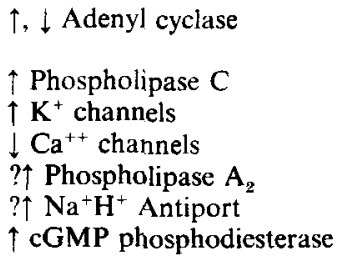 \\
\hline Ion channels & Multiple subunits & $\begin{array}{l}\text { Nicotinic } \\
\text { acetylcholine } \\
\text { GABA }_{\text {A }} \\
\text { Glycine }\end{array}$ & $\begin{array}{l}\text { Sodium channels } \\
\text { Chloride channels }\end{array}$ \\
\hline $\begin{array}{l}\text { Guanylate } \\
\text { cyclase }\end{array}$ & $\begin{array}{l}\text { Single hydrophobic } \\
\text { domain }\end{array}$ & $\begin{array}{l}\text { Atrial natriuretic } \\
\text { peptide } \\
\text { Sea urchin egg } \\
\text { peptides }\end{array}$ & $\uparrow$ cGMP \\
\hline Tyrosine kinase & $\begin{array}{l}\text { Single hydrophobic } \\
\text { domain }\end{array}$ & $\begin{array}{l}\text { Insulin } \\
\text { Insulin-like growth } \\
\text { factor } 1 \\
\text { EGF } \\
\text { PDGF } \\
\text { CSF }\end{array}$ & Protein tyrosine kinase \\
\hline
\end{tabular}

The general structural features and effector systems are illustrated for some classes of receptors for which deduced amino acid sequences are known. See text for details and literature references. 


\section{REVIEW ARTICLES}

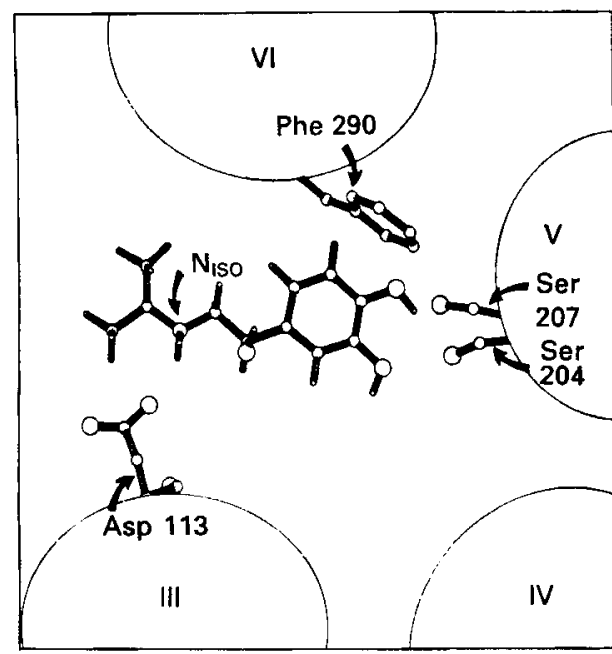

Fig. 3. Proposed structural model for the ligand binding site of the $\beta A R$. The ligand isoproterenol is shown, as viewed from outside the cell, surrounded by several of the proposed transmembrane helices. The Roman numerals indicate the location of the proposed transmembrane helix within the sequence of the $\beta$ adrenergic receptor with I being closest to the amino terminus and VII being closest to the carboxyl terminus. The proposed locations of the $a_{s p^{113}}$, phe ${ }^{290}$, ser ${ }^{214}$ and ser ${ }^{207}$ side chains are indicated. The location of the cationic amine of isoproterenol in the binding pocket is indicated by $N_{i 80}$. Figure and legend modified from reference 3 by permission of The FASEB Journal, Vol. 3 . I828, 1989.

adrenergic receptor that has been proposed for binding to agonists is similar to that for the retinal chromophore in rhodopsin. Aspartate 113 in the third predicted membrane spanning region of the $\beta_{2} \mathrm{AR}$ is necessary for both agonist and antagonist binding while serine resides in the fifth and seventh hydrophobic regions are necessary for agonist binding $^{3}$ (Fig. 3). Thus, the drugs which activate $G$ protein-linked receptors associate with the hydrophobic membrane spanning regions in an ideal position to produce a conformational change in the intracellular loops of the receptor that interact with the $\mathrm{G}$ protein.

\section{Protein Conformational Changes}

Although the first crystal structure of an integral membrane protein has recently been solved, ${ }^{14}$ no high resolution structure of a receptor is known. Thus, the molecular details underlying ligandinduced protein conformational changes can be best appreciated by considering allosteric proteins whose crystal structures are available. Hemoglobin and two bacterial proteins, the tryptophan repressor and the enzyme aspartate transcarbamylase (E.C. 2.1.3.2) from $E$. coli are well studied allosteric proteins for which high resolution structures of both liganded and unliganded forms are known. The bind- ing of tryptophan to the trp aporepressor appears to modulate the biological function of the protein (i.e. its DNA binding affinity) in a particularly simple manner. The tryptophan becomes wedged between hinged domains of the aporepressor, forcing two flexible loops out from the main core of the protein. ${ }^{15}$ The spacing of those domains is then optimal for binding in two adjacent major grooves of the DNA helix (Fig. 4). Although there are two tryptophan binding sites in the aporepressor, each tryptophan appears to bind independently and there is no cooperativity in the structural transition to the active form

Aspartate transcarbamylase illustrates the effects of regulatory ligand binding to a more complex protein system. This enzyme catalyzes the committed step in pyrimidine biosynthesis, the formation of carbamyl-aspartate from carbamyl-phosphate and asparate. Because of its central role in nucleotide metabolism, it is regulated both by substrates, aspartate and carbamylphosphate, and by allosteric effectors, ATP and CTP. Most of the data regarding regulation of this enzyme is consistent with a two-state model in which one state $(T)$ is less active than the other $(\mathrm{R}) .^{16}$ Activating ligands such as substrates and ATP shift the equilibrium to the $\mathrm{R}$ state while the inhibitory ligand, CTP, shifts it back to $T^{16}$ The aspartate transcarbamylase
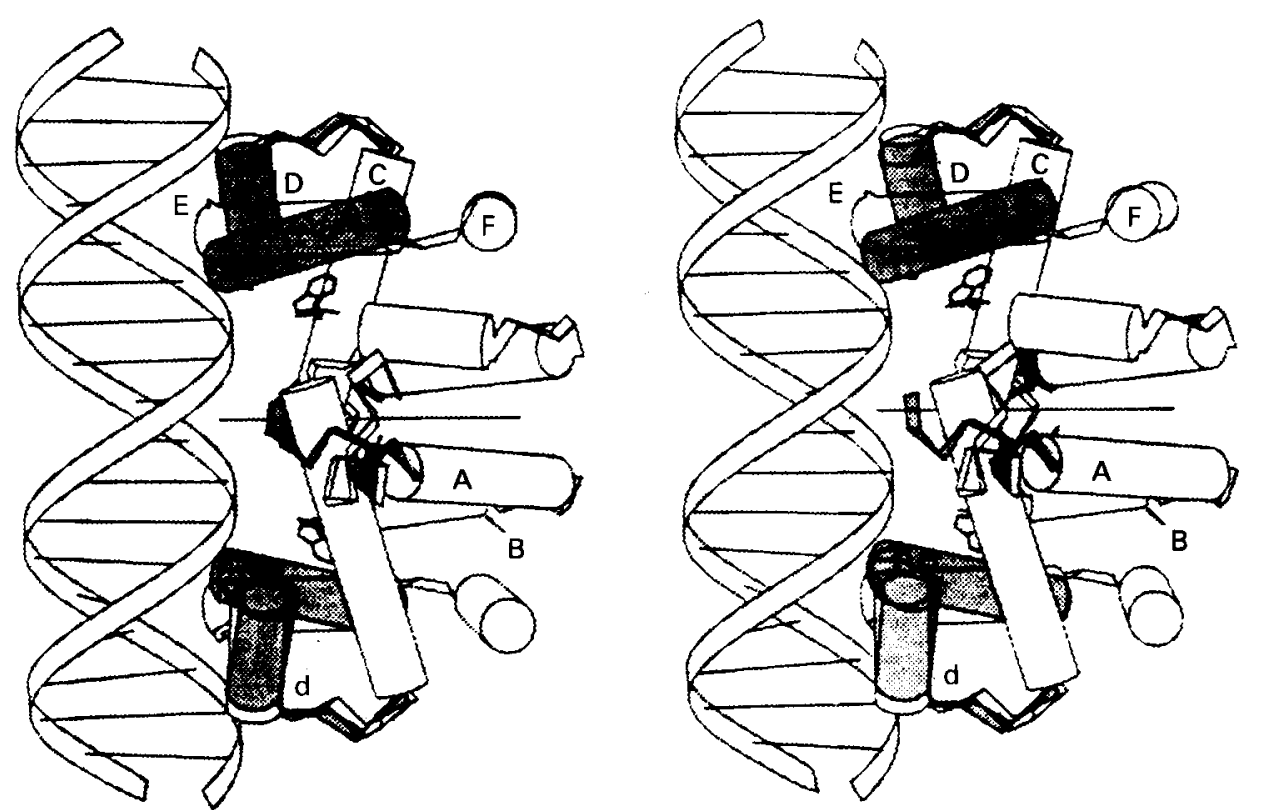

Fig. 4. Schematic drawing of the trp aporepressor conformational change upon binding tryptophan. The structures without and with tryptophan bound are superimposed with the regions exhibiting the greatest movement shown in gray shading. Cylinders represent $\alpha$-helices and the operator DNA is represented as a double helix. Tryptophan binding between the $C$ and $E$ helices causes the $D$ and $E$ helices to shift out from the core of the molecule. The outward movement results in tight binding of the liganded repressor to the operator DNA. Figure and legend modified from reference 15 with permission from Nature Vol. 327 pp. 591-597 copyright (C) 1987 Macmillan Magazines Ltd.

complex has six catalytic and six regulatory subunits. Each substrate binding and catalytic site includes amino acid residues from two catalytic subunits. A stable carbamylaspartate analog, Lphosphonoaspartate (PALA) has been used to study the X-ray crystal structure of the liganded enzyme. ${ }^{17}$ The binding of a single PALA molecule is sufficient to convert the entire dodecameric complex into the $R$ state. In contrast to the steric effect of tryptophan to open the structure of the trp aporepressor, PALA binding to asparate transcarbamylase results in a more closed, but more active, structure of the catalytic site. Several amino acid residues undergo large shifts in the transition from the $T$ to the $R$ state. Lys84 of the adjacent catalytic subunit exhibits a dramatic shift into the catalytic site. Its $\alpha$ chain moves $6 \AA$ and its side chain $10 \AA$
toward the ligand molecule. ${ }^{17}$ The negative charges of the carboxylate groups on PALA produce a bridge between the positive charges on argl67 and $\arg 229$ causing an entire $\alpha$ helical chain to shift. This motion breaks salt bridges and forms new ones that are thought to be crucial for the change in quaternary structure of the complex. ${ }^{17}$

Aspartate transcarbamylase and hemoglobin have been considered to be good examples of the allostery theory of Monod et al. ${ }^{18}$ since two state thermodynamic mechanisms have been able to account for most of the experimental

.


data. ${ }^{16}$ In both cases, there are now indications that an additional conformational state of the protein is necessary to account for thermodynamic ${ }^{19}$ or structural ${ }^{20}$ data. Despite these new conclusions, the fundamental concept of ligand binding energy perturbing a thermodynamic equilibrium of protein conformational states appears to be confirmed. ${ }^{19}$ A regulatory protein for which three structural forms have been directly demonstrated is citrate synthetase. $^{21}$ In this case, an induced fit mechanism has been proposed. In addition to the major functional states of proteins identified by ligand binding and enzyme activity, proteins appear to have multiple conformational substates. ${ }^{22}$ An ensemble of conformational substates makes up a single functional state. The most direct demonstration of these substates comes from low temperature studies of hemoglobin. ${ }^{22}$ Molecular dynamic simulations of protein motion have also begun to suggest the existence of substates. ${ }^{23}$ At normal biological temperatures, there would be rapid interconversions between the substates, resulting in the appearance of a small number of functional states.

\section{Identification of Receptor Conformational Changes}

Only limited direct studies are available on conformational changes of classical receptors (see discussion of electron microscopic images of the nicotinic acetylycholine receptor above). However, several indirect approaches have been used to study receptor conformation. Receptor conformation can alter : (1) spectral properties of covalent or reversibly bound fluorescent reporter groups, (2) the sensitivity of the receptor to various enzymes (including proteases and kinases), (3) the sedimentation or chromatographic properties of the receptor, (4) the affinity of binding of radioligands (especially agonists), or (5) the functional state of the receptor. Thus, by monitoring any of these properties of the receptor, changes in conformation can be iollowed.

The best example of a signal transducing protein for which spectral information has provided a detailed view of protein conformational changes is rhodopsin. ${ }^{24}$ Following the initial isomerization of the retinal chromophore to the all trans form, the spectral properties of the retinal change as the opsin traverses a sequence of conformations. The lifetimes of these conformations range from picoseconds to seconds. Metarhodopsin II, identified by a maximal absorbance at $380 \mathrm{~nm}$, appears to be the conformation of rhodopsin that binds and activates transducin, the $G$ protein which mediates visual transduction. ${ }^{24}$ The presence of the retinal chromophore provides a unique tool for studying rhodopsin activation and the accompanying protein conformational changes.

For receptors that don't have a simple spectroscopic handle, changes in agonist binding affinity have been used to infer and characterize receptor conformations. This approach has proven effective for the nicotinic acetylcholine receptor ${ }^{25,26}$ and more recently for the $\alpha_{2}$ AR. ${ }^{27}$ Agonists are most useful because antagonist affinities generally do not depend on the conformation of the receptor. Indeed, allostery theory predicts that the active receptor conformation would have a high affinity for agonist relative to the non-activated receptor while there would be no difference between the affinity of active and inactive receptors for antagonist. In the case of the nicotinic receptor, the inactivated or desensitized states also have a unique (and relatively high) affinity for agonists, thus making them accessible to detection by this approach. Depending on the abundance of the receptor, either radiolabelled ${ }^{25,27}$ or fluorescently labelled ${ }^{26}$ agonists have been used. This approach is even more powerful when combined with in vitro measures of receptor function. ${ }^{25,26,28}$

At least four conformational states of the nicotinic acetylcholine receptor are necessary to account for the binding and response data. In the absence of agonist, the Torpedo nicotinic acetylcholine receptor exists in an equilibrium with $80 \%$ of the receptor in a resting conformation and $20 \%$ in a desensitized conformation that binds agonist with high affinity. ${ }^{26}$ Within microseconds after binding, agonist shifts the receptor into the active conformation in which the intrinsic cation channel is open. ${ }^{29}$ The receptor is then converted on a time scale of hundreds of milliseconds to a desensitized conformation that binds agonist with an intemediate affinity. ${ }^{25,26}$ Subsequently, there is a slow desensitization such that nearly all of the receptor is converted to the high affinity desensitized state. ${ }^{25,26}$ These two distinct desensitized states have also been identified by single channel electrophysiological methods and were found to have kinetic properties similar to those seen biochemically. ${ }^{30}$ Thus the nicotinic acetylcholine receptor can exist in at least four functional states, which presumably reflect distinct con- formations, a resting state, the active state and two distinct desensitized states. $^{2}$

Conformational changes of ARs and other receptors that are coupled to $G$ proteins have been more difficult to study for two reasons. First, the receptors are present in cell membranes in very small amounts. Second, the coupling of the receptor to the $G$ protein greatly increases the receptor's apparent affinity for agonists. ${ }^{8}$ Perhaps the best evidence that agonists can cause a conformational change in these receptors without a $G$ protein being present comes from the observation that $a$ unique protein kinase, termed $\beta \mathrm{AR}$ kinase can phosphorylate the purified $\beta$ AR and $\alpha_{2}$ AR only when they are occupied by agonist. ${ }^{31}$

While the $\beta \mathrm{AR}$ mediates stimulation of adenylyl cyclase, the $\alpha_{2} A R$ as well as several other receptor types ${ }^{32}$ inhibit adenylyl cyclase through the action of the inhibitory guanine nucleotide regulatory protein, $G_{i}$. These receptors also mediate a variety of other cellular signals through $\mathrm{G}_{i}$ or $\mathrm{G}_{\mathrm{i}}$-like proteins. ${ }^{32}$ A high affinity radiolabelled full $\alpha_{2}$ agonist makes the $\alpha_{2}$ AR ideal for the use of agonist affinity measurements in detecting receptor conformational changes. ${ }^{27}$ As with other $G$ protein coupled receptors, $\alpha_{2}$ agonist binding affinity is reduced by conditions that disrupt receptor $G$ protein coupling. ${ }^{33,34}$ The ability of purified $G$ proteins to restore high affinity agonist binding to $\beta^{35}$ and $\alpha_{2}^{36}$ adrenergic and muscarinic acetylcholine ${ }^{37}$ receptors directly demonstrates the role of protein-protein interactions in conformational changes of $\mathrm{G}$ protein-coupled receptors. Unfortunately, it has not been possible to form receptor $G$ protein complexes in detergent solutions; the membrane environment is necessary, possibly to correctly orient the proteins for interaction. Kinetic modelling of the time course of $\alpha_{2}$ agonist binding in membrane preparations from human platelets shows that approximately $30 \%$ of the $\alpha_{2}$ receptors are coupled to $G_{i}$ before agonist is added, then the agonist induces further coupling. ${ }^{27}$ The temperature dependence of the agonistinduced coupling suggests that the lipid bilayer plays an important role in this process either because there is diffusion of the proteins in the membrane or a protein conformational change occurs which is dependent on the state of the membrane lipids. ${ }^{38}$ The concept of diffusional coupling of $\beta$ receptors and $G_{s}$ (or adenylyl cyclase) has been a major paradigm in the theory of $G$ 


\section{REVIEW ARTICLES}

protein-linked receptors and is supported by many experimental observations. ${ }^{39,40 .}$

Parallel measurements of adenylyl cyclase inhibition and $\alpha_{2}$ agonist binding using rapid kinetic techniques have shown that the rate-limiting step in the $\alpha_{2}$ response is distal to agonist binding. ${ }^{41}$ Both activation and inhibition of adenylyl cyclase in biological membranes $^{28}$ are much faster than would be expected from measurements of receptor-stimulated guanine nucleotide binding in reconstituted systems. ${ }^{37,40}$ In platelet membranes, the rate-limiting step in inhibition of adenylyl cyclase appears to be the conformational change of the $\mathrm{G}_{\mathrm{i}}$-GTP complex. $^{28}$ These conclusions are based on indirect approaches such as kinetic modelling of ligand binding and inhibition of adenylyl cyclase in biological membranes. Future work in this area will require new methods to probe more directly the conformational changes of the receptors and the $G$ proteins. A complete understanding of these mechanisms in intact cells will also need to account for the role of membrane lipids and cytoskeletal elements in regulating the organization and movement of membrane proteins.

\section{Unanswered Questions}

Despite the explosion of information about the primary structure of membrane receptors there are many unanswered questions regarding tertiary and quaternary structure. Also, the dynamic aspects of receptor function are even less well understood. Some areas that must be addressed to obtain a true molecular understanding of receptor function can be outlined in the following questions: (1) Are there relatively few conformational states for receptors with fluctuations around those states or are there hundreds of stable conformational states? (2) What implications do these multiple receptor conformations have for the use of static structural information in the design of drugs? (3) Are the structural interactions that result in receptor activation necessary and sufficient for desensitization or can agonist drugs be designed that would not result in desensitization? (4) Do receptors complexed to $G$ proteins with different nucleotides bound have different conformations? (5) How does the membrane location of receptors and $G$ proteins affect their conformational state and do membrane lipids or the cytoskeleton modulate their interactions and conformational changes?
We may get hints about the answer to the first of these questions by reference to soluble proteins for which the structures are better established. In those cases it appears that there are a relatively small number of stable states of the proteins. Also, single channel electrophysiological studies of ion channel coupled receptors and voltage sensitive ion channels indicate that while there are increasing numbers of states being identified, there is not a continuum of states as indicated by the discrete single channel conductances that are observed. The answers to some of the other questions must await the development of methods to study the structure and function of the membrane receptors more directly.

\section{Acknowledgements}

The authors' work cited in this article was supported by NSF DCB 8409333 , HL 37551 and GM 39561. This article was prepared during the tenure of an Established Investigatorship award (to R.R.N.) from the American Heart Association and Genentech, Inc. The authors thank Dr. Catherine Strader for providing a manuscript prior to publication. We would also like to acknowledge the many other scientists whose important original contributions to this field we have been unable to cite because of space limitations.

\section{REFERENCES}

1 Cuatrecasas, P. (1972). Isolation of the insulin receptor of liver and fat-cell membranes. Proc. Natl. Acad. Sci. USA 69, 318-322.

2 Changeux, J-P., Devillers-Thiery, A. \& Chemouilli, P. (1984). Acetylcholine receptor: an allosteric protein. Science 225, 1335-1345.

3 Strader, C. D., Sigal, I. S. \& Dixon, R. A. F. (1989) Structural basis of $\beta$-adrenergic receptor function. FASEB J. 3, 1825-1832.

4 Peralta, E. G., Ashkenazi, A., Winslow, J.W. Smith, D. H., Ramachandran, J. \& Capon, D. J. (1987) Distinct primary structures, ligand-binding properties and tissue-specific expression of four human muscarinic acetylcholine receptors. EMBO J 6, 3923-3929.

5 Yarden, Y., Escobedo, J. A., KuanG, W-J., YangFeng, T. L., Daniel, T. O., Tremble, P. M., Chen, E. Y., ANDo, M. E., Harkins, R. N., Franke, U., Fried, V. A., Ulrich, A.\& Williams, L. T. (1986). Structure of the receptor for platelet-derived growth factor helps define a family of closely related growth factor receptors. Nature 323, 226-232.

6 Chinkers, M., Garbers, D. L., Chang, M-S., Lowe, D. G., ChIN, H., Goeddel, D. V. \& Schulz, S. (1989). A membrane form of guanylate cyclase is an atrial natriuretic peptide receptor. Nature 338, 78-83.

7 ApPlebury, M. L. \& Hargrave, P. A. (1986). Mol ecular biology of the visual pigments. Vision Research $\mathbf{2 6}$ 1881-1895

8 GILMAN, A. G. (1987). G proteins: transducers of receptor-generated signals. Annu. Rev. Biochem. 56 615-649.

9 Schofield, P. R., Darlison, M. G., Juitta, N., BuRT, D. R., Stephenson, F. A., Rodriguez, H., Rhee, L. M., Ramachandran, J., Reale, V., Glencorse, T. A., Sefburg, P. H. \& BarNard, E. A. (1987). Sequence and functional expression of the GABA receptor shows a ligand-gated receptor super-family. Nature 328, 221-227.
10 Unwin, N., Toyoshima, C. \& Kubalek, E. (1988) Arrangement of the acetylcholine receptor subunits in the resting and desensitized states, determined by cryoclectron microscopy of crystallized Torpedo postsynaptic membranes. J. Cell Biol. 107, 1123-1138.

11 DANI, J. A. (1989). Site-directed mutagenesis and single-channel currents define the ionic channel of the nicotinic acetylcholine receptor. TINS 12, 125-128.

12 Khorana, H. G. (1988). Bacteriorhodopsin, a membrane protein that uses light to translocate protons. $J$ Biol. Chem. 263, 7439-7442.

13 Dohlman, H. G., Bouvier, M., Benovic, J. L. Caron, M. G. \& LeFKowitz, R. J. (1987). The multiple membrane spanning topography of the beta $_{2}$-adrenergic receptor. Localization of the sites of binding, glycosyl ation, and regulatory phosphorylation by limited proteolysis. J. Biol. Chem. 262, 14282-14288.

14 DeISENhOFER, J., EpP, O., Miki, K., Huber, R. \& MICHEL, H. (1985). Structure of the protein subunits of the photosynthetic reaction centre of Rhodopseudomonas viridis at $3 \mathrm{~A}$ resolution. Nature 318, 618-624.

15 Zhang, R.-G., JOACHIMIAK, A., LAWSON, C. L SChevitz, R. W., OTWTNOWSKI, Z. \& SigleR, P. B (1987). The crystal structure of $t r p$ aporepressor at $1.8 \AA$ shows how binding tryptophan enhances DNA affinity. Nature 327, 59]-597.

16 Schachman, H. K., (1988). Can a simple model account for the allosteric transition of aspartate transcarbamoylase. J. Biol. Chem. 263, 18583-18586.

17 Krause, K. L., Volz, K. W. \& Lipscomb, W. N. (1987). $2.5 \AA$ Structure of aspartate carbamoyltransferase complexed with the bisubstrate analog $\mathrm{N}$-(phos phonoacetyl)-L-aspartate. J. Mol. Biol 193, 527-553.

18 Monod, J., Wyman, J. \& ChangeuX, J-P. (1965). On the nature of allosteric transitions: a plausible model. $J$ Mol Biol 12, 81-118.

19 ACKers, G. K. \& SMith, F. R. (1987). The hemoglobin tetramer: A three-state molecular switch for control of ligand affinity. Annu. Rev. Biophys. Biophys. Chem. 16, 583-609.

20 Govaux, J. E. \& Lipscomb, W. N. (1989). Structural transitions in crystals of native aspartate carbamoyltransferase. Proc. Natl. Acad. Sci. USA 86, 845-848.

21 Weigand, G. \& Remington, S. J. (1986). Citrate synthetase: structure, control and mechanism. Annu. Rev. Biophys. Biophys. Chem. 15, 97-117.

22 Frauenfelder, H., Parak, F. \& Young, R. (1988) Conformational substates in proteins. Annu. Rev. Biophys. Biophys. Chem. 17, 451-479.

23 Elber, R. \& Karplus, M. (1987). Multiple conformational states of proteins: a molecular dynamics analysis of myoglobin. Science 235, 318-321.

24 Chabre, M. (1985). Trigger and amplification mechanisms in visual phototransduction. Annu. Rev Biophys. Biophys. Chem. 14, 331-360.

25 Neubig, R. R., BOYd, N. D. \& COHEN, J. B. (1982) Conformations of Torpedo acetylcholine receptor associated with ion transport and desensitization. Biochemistry 21, 3460-3467.

26 Heidmann, T., Bernhardt, J., Neumann, E. \& Changeux, J-P. (1983). Rapid kinetics of agonist binding and permeability response analysed in paraliel on acetylcholine receptor rich membranes from Torpedo marmorata. Biochemistry 22, 5452-5459.

27 Neubig, R. R., Gantzos, R. D. \& Thomsen, W. J. (1988). Mechanism of agonist and antagonist binding to $\alpha_{2}$ adrenergic receptors: evidence for a precoupled receptor-guanine nucleotide protein complex. Biochemistry 27, 2374-2384.

28 Thomsen, W. J. \& Neubig, R. R. (1989). Rapid kinetics of $\alpha_{2}$-adrenergic inhibition of adenylate cyclase. Evidence for a distal rate limiting step. Biochemistry, (In the press).

29 Land, B. R., Salpeter, E. E. \& Salpeter, M. M (1981). Kinetic parameters for acetylcholine interaction in intact neuromuscular junction. Proc. Natl. Acad. Sci. USA 78, 7200-7204.

30 Sakmann, B., Patlak, J. \& Neher, E. (1980). Single acetylcholine-activated channels show burst-kinetics in presence of desensitizing concentrations of agonist. Nature 286, 71-73.

31 Benovic, J. L., Staniszewski, C., Mayor, F. J. R. CARON, M. G. \& Lefkowitz, R. J. (1988). betaAdrenergic receptor kinase. Activity of partial agonists for stimulation of adenylate cyclase correlates with ability to promote receptor phosphorylation. J. Biol. Chem. 263, 3893-3897.

32 Limbird, L. E. (1988). Receptors linked to inhibition of adenylate cyclase: additional signaling mechanisms. FASEB J. 2, 2686-2695.

33 Limbird, L. E. \& SPECK. J. L. (1983). N-ethyl- 
maleimide, elevated temperature, and digitonin solubilization eliminate guanine nucleotide but not sodium effects

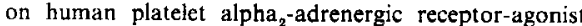
interactions. J. Cyclic. Nucleotide. Protein. Phosphor. Res. 9, 191-201.

34 Kurose, H., Katada, T., Amano, T \& Ui, M. (1983) Specific uncoupling by islet-activating protein, pertussis toxin, of negative signal transduction via alphaadrenergic, cholinergic, and opiate receptors in neuroblastoma $\times$ glioma hybrid cells. J. Biol. Chem. 258 , $4870-4875$.

35 Cerione, R. A. Codina, J., Benovic, J. L. Lefkowitz, R. J., Birnbaumer, L. \& Caron, M. G. (1984). The mammalian $\beta_{2}$-adrenergic receptor: Reconstitution of functional interactions between pure receptor and pure stimulatory nucleotide binding protein of the adenylate cyclase system. Biochemistry 23, 4519 4525 .
36 KiM, M. H. \& Neubig, R. R. (1987). Membrane reconstitution of high-affinity $\alpha_{2}$ adrenergic agonist binding with guanine nucleotide regulatory proteins. Biochemistry 26, 3664-3672

37 Tota, M. R., Kahlfr, K. R. \& Schimerlik, M. I (1987). Reconstitution of purified porcine atrial muscarinic acetylcholine receptor with purified atrial inhibitory guanine nucleotide binding protein Biochem. istry 26, 8175-8182.

38 Gantzos, R. D. \& Neubig, R. R. (1988). Temperature effects on $\alpha_{2}$-adrenergic receptor- $G_{1}$ interactions. Biochem. Pharmacol. 37, 2815-2821.

39 Tolkovsky, A. M. \& Levitzk1, A. (1978). Mode of coupling between the $\beta$-adrenergic receptor and adenylate cyclase in turkey erythrocytes. Biochemistry $17,3795-3810$.

40 Brandt, D. R. \& Ross, E. M. (1986). Catecholamine-stimulated GTPase cycle. Multiple sites of regulation by $\beta$-adrenergic receptor and $\mathrm{Mg}^{2+}$ studied in reconstituted receptor- $G$ vesicles. J. Biol. Chem $\mathbf{2 6 1}$ 1656-1664.

41 ThOMSEN, W. J. Rapid kinetic studies of $\alpha_{2}$ adrenergic inhibition of adenylate cyclase, Ann Arbor, MI. Ph.D Thesis, University of Michigan, 1989.

RICHARD NEUBIG is at the Department of Pharmacology, M6322 Medical Science Bldg. 1, and William J.

Thomsen is at the Department of Pharmacology University of Michigan Medical School, Ann Arbor, MI 48109-0626, USA.

\title{
Regulation of Pituitary Peptides by the Immune System
}

\author{
Nicholas R. S. Hall and Maureen P. O'Grady
}

\section{Summary}

It has long been thought that the central nervous system is able to influence the progression of disease. Furthermore, there is now overwhelming evidence that the communication pathways are bidirectional. A variety of immune system peptides are now known to be capable of transmitting information from the immune system to the central nervous system. These immunotransmitters include interleukins, interferons and thymosine peptides which have the capability of modulating slow-wave sleep as well as the release of neuro- and pituitary peptides. In some instances, release of these peptides during early development may have long lasting, if not permanent effects upon the normal development of neuroendocrine circuits. Collectively these various brain mediated events appear to contribute in various and diverse ways to defense against pathogens. It is becoming more and more apparent that certain abnormalities within the immune system may be the consequence of a neurological abnormality. The converse is also true.

\section{Introduction}

For thousands of years a role for emotional state in modulating the balance between health and disease has been suspected. As early as the second century A.D., the Greek philosopher Galen reported that melancholy individuals are more susceptible to cancer than are sanguine individuals. ${ }^{1}$ In recent years, investigators have successfully correlated episodes of stress with debilitated health. These include models in which bereaved individuals have been found to have depressed immunity ${ }^{2}$ as well as models using medical students who have been found to have increased susceptibility to viral infections correlated with preparation for academic exams. $^{3}$ Since anxiety and negative emotional states can sometimes be correlated with activation of the autonomic nervous system as well as with increased secretion of ACTH and subsequently cortisol, the pituitary-adrenal axis has been suspected as serving as the conduit via which the central nervous system is able to modulate the activity of the immune system (see ref. 4). Evidence that immune system tissues are extensively innervated by projections from the sympathetic branch of the autonomic nervous system is reviewed elsewhere. ${ }^{5}$ In addition, virtually every hormone produced by cells within the pituitary gland is able to either directly or indirectly influence the biological activity of lymphocytes and/or macrophages (see ref. 6). Because of the afferent links with the nervous system, it is widely accepted -although not proven - that it is via the autonomic nervous system and specific neuroendocrine circuits that emotional state is ultimately transduced into an immunomodulatory signal.

If the central nervous system does indeed modulate the course of immune responsiveness, then there ought to be a mechanism via which the brain can monitor the level of activity within the immune system. Similar mechanisms exist for various endocrine systems within the body and are manifested as either positive and/or negative feedback loops. A typical mechanism would involve the inhibition of releasing factors within the hypothalamus by excessively high levels of an endocrine target gland's products and increased release when levels of the target organ's hormone were low. A number of signals emanating from within the immune system compartment might well serve in such a capacity. These would also include the antigen which would serve as the trigger of the immunologic cascade. Other signals might be in the form of cytokines, many of which are active in the brain.

While not directly related to regulation of the immune system, the various brain controlled processes that are influenced by immune system peptides can be considered as contributing to the well being of the host. For example, interleukin 1 is capable of stimulating slow wave sleep as well as a fever response. ${ }^{8}$ It is during this particular stage of sleep that growth hormone is released which has tropic- and growthpromoting effects and which are undoubtedly beneficial during a period when tissue repair would be needed following infection of the host. Furthermore, hyperthermia results in an inhospitable environment for many microorganisms and facilitates the ac- 